\title{
Logistic Regression Model to Investigate the Risk Factors for Glaucoma
}

\author{
Amaal Sadeq Hamoodi \\ Mathematics Department, College of Education, Mustansiriya University, Baghdad 10052, Iraq
}

Corresponding Author Email: damal.sadiq@gmail.com

https://doi.org/10.18280/mmep.080606

Received: 21 June 2021

Accepted: 8 October 2021

\section{Keywords:}

ethnicity, logistic regression model, risk factors, statistical analysis

\begin{abstract}
Many studies have found that age, race, gender, past family history, and intraocular pressure (IOP) of the eyes are key risk factors for glaucoma disease. The current study aims to evaluate the relationship between glaucoma and various glaucoma risk factors in the Arabian ethnicity using a cohort cross-sectional observational design. Therefore, the current study is targeted at building a regression model to estimate the probability of injury to glaucoma disease, which is one of the serious diseases that affect the eyes. It uses the logistic regression model, which is one of the modern non parametric methods, and a cohort cross-sectional observational design. The study included a total of 136 glaucoma patients. The findings show that there is no link between gender and glaucoma $(\mathrm{p}=0.202)$, while there is a link between age and glaucoma $(\mathrm{p}=0.004)$. Furthermore, the findings demonstrate that there is no association between diabetic mellitus $(\mathrm{DM})$ and glaucoma $(\mathrm{p}=0.273)$, although there is a relationship between hypertension and healing degree $(\mathrm{p}=0.035)$ and diabetes and healing degree $(\mathrm{p}=$ 0.001 ). The findings also show that the factors affecting injury are: age, gender, pressure, and geographical location, and that diabetes and climatic factors are not influential. Current findings may aid in the development of intervention strategies that will raise glaucoma awareness in the future.
\end{abstract}

\section{INTRODUCTION}

The major cause of global blindness is glaucoma, followed by cataracts. It is a main community health problem, being the leading cause of irretrievable visual impairment worldwide [1].

Normally, glaucoma is categorized into open angle glaucoma and closed angle one, also both types can further be classified as either primary or secondary. The primary open angle glaucoma (POAG) is the utmost common type of glaucoma contributing for about $74 \%$ of all glaucoma cases, the estimated number of POAG cases in 2020 is 53 million due to population ageing. In 2040, the estimated universal number of individuals with glaucoma will growth to $111.8 \mathrm{~m} \mathrm{[2].}$

The POAG is the common kind of glaucoma, it is characterized by the advanced deterioration of retinal ganglion cells (RGCs) and the axons in the optic nerve, causing structural changes in the head of the optic nerve which lead to visual field defects [3]. The sieve-like structure, lamina cribrosa, in the sclera which allows flow of the RGC and central retinal vessels, appears to be the main site of axonal injury in glaucoma [4]. The elevated intraocular pressure (IOP) is regarded the most important changeable risk factor of glaucomatous optic neuropathy (GON). Though, in a noteworthy that some patients characterized of normal tension glaucoma (NTG) in spite of normal IOP. So the other risk factors might also be included in the optical neuropathy of POAG [5].

Many epidemiological studies proposed that the chief risk factors for glaucoma are intraocular pressure (IOP), family history of the disease, age, race and gender [6-11]. One of the exceptional factors found in studies is the effect of race on the type of glaucoma, some researchers reports that African Americans are more prone to be hit by open angle glaucoma than whites [2].

POAG appears earlier in black people than in other ethnic groups and is closely connected to age. All of the patients are 85 years old, and the prevalence is substantially higher in those over 90. The largest prevalence is among older Hispanic or Latino adults (18\%), followed by black people (15\%), white people (7\%), and Asian people (5\%) [12].

The second kind of glaucoma is Primary angle closure glaucoma (PACG), which accounts for approximately $25 \%$ of all glaucoma cases and is a leading cause of blindness [13, 14]. POAG is growing more popular since studies suggest that one in every two glaucoma patients is ignorant of their condition $[15,16]$. Therefore, determining the disease's spread is a timeconsuming and labor-intensive process that necessitates numerous surveys.

Few studies have been undertaken in the Middle East region, and they have revealed a significant frequency of cataract, glaucoma, diabetic retinopathy, and dry eye disease [17-19]. Therefore, the goal of the current investigation is to address a knowledge gap by assessing the awareness of glaucoma and its risk factors among the Iraqi population using a logistic regression model.

\section{METHODS}

\subsection{Design and area}

This is a cohort cross-sectional observational study that was 
carried out on participants who visited the eye clinic at Ibn AlHaitham Hospital in Iraq between June 2019 and May 2020. The Institutional Review Board (IRB) granted us ethical approval, and all patients agreed to participate in this study and consented. This research was carried out in accordance with the latest Helsinki Declaration (2013). Figure 1 shows the schematic diagram of current study.

The number of pages for the manuscript must be no more than ten, including all the sections. Please make sure that the whole text ends on an even page. Please do not insert page numbers. Please do not use the Headers or the Footers because they are reserved for the technical editing by editors.

\subsection{Criteria for inclusion and exclusion}

The study samples were random and exceeded 300 samples. The sample was filtered for the reasons that will be discussed in this section so that the final number becomes 136 patients. The stage of exclusion or inclusion of participants in this study included two stages. In the first examination stage, all non-
Iraqi participants were excluded, and Iraqi patients were included exclusively. This stage also includes the inclusion of patients with POAG or PACG in at least 1 eye.

The second examination stage included the inclusion of patients with both types of diseases under study exclusively and the exclusion of others. People who have had cataract surgery and those with systemic diseases that may cause a visual field (VF) are also excluded at this stage. In addition to those, the study exclusions are those who suffer from keratoconus and corneal dystrophy. Other patients excluded at this stage are those who use contact lenses.

\subsection{Parameters measured}

Glaucoma was diagnosed by an ophthalmologist based on IOP readings, optic nerve alterations, and visual field deficits. Furthermore, patients' demographic data, such as gender, age, and ethnicity, as well as past ocular and medical history, such as hypertension and diabetes, were collected.

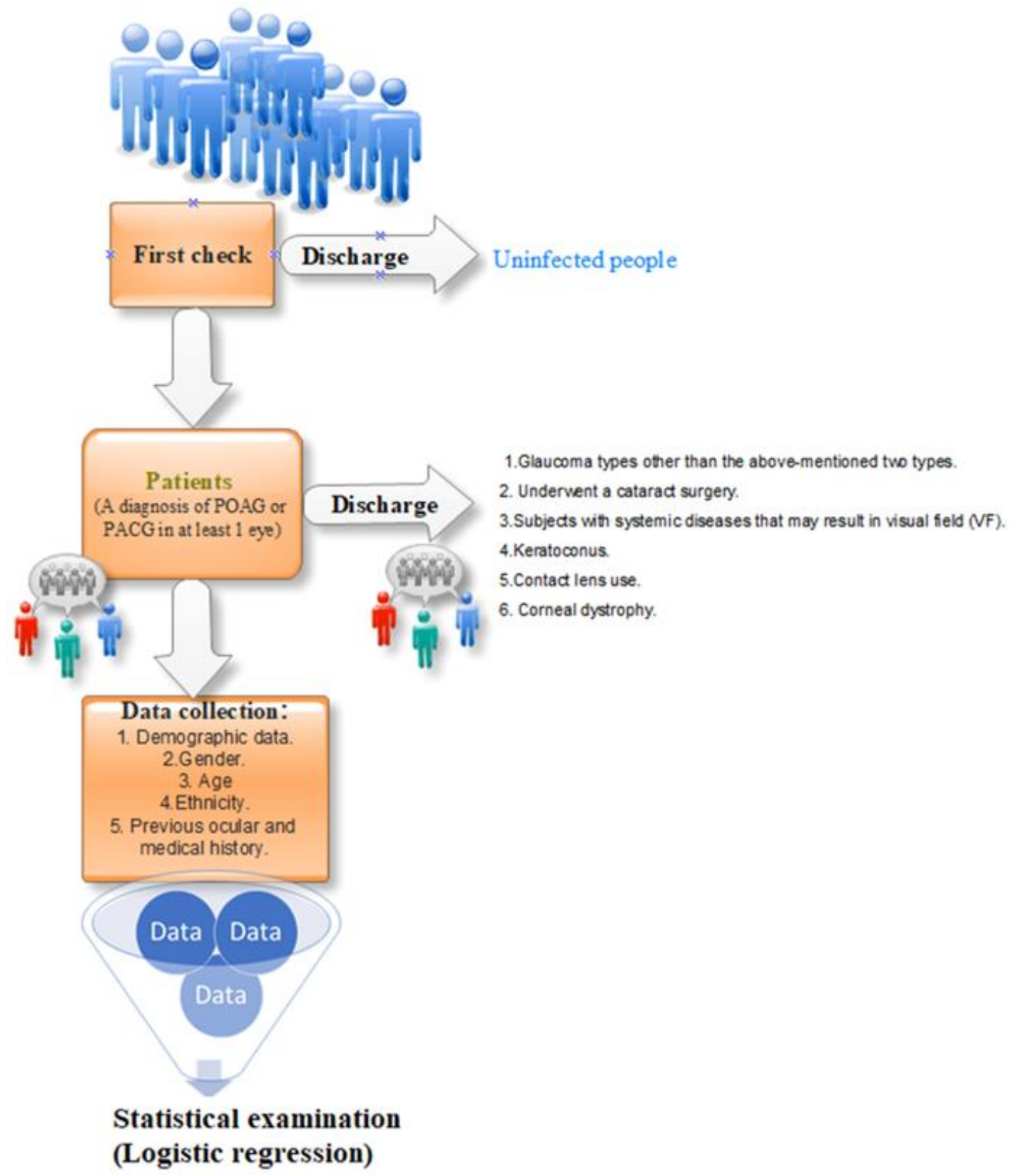

Figure 1. Schematic diagram of current study 


\subsection{Statistical analysis}

SPSS ver. 24.0 (Chicago, USA) was used in the current study's statistical analysis. It first identified the sample population, then classified them according to gender, then recorded the data using numbers (percentages) and the mean (standard deviation). To consider the influence of gender on the development of glaucoma, a logistic regression with a generic estimating equation was used. Pearson's correlation was utilized to investigate the relationship between age and the other parameters. To specify statistical relationship or significance, we utilized p less than 0.05 .

\section{RESULTS}

The study sample included 136 Iraqi patients, 75 (55.1\%) of whom were males and $61(44.9 \%)$ of whom were females, with a mean age of 58.3 years $(\mathrm{SD}=2.4)$. Table 1 depicts the distribution of age ranges for all ages.

The largest number of the study sample was 45 patients, who were between 61-70 years old, followed by 27 patients, who were between 71-80 years old. Regarding the chronic diseases, 105 patients (77.2\%) of the study suffered from hypertension, in addition to 51 patients $(37.5 \%)$ from the study sample suffer from diabetes.
A simple linear regression test was performed to examine the relationship between gender disparity and the development of glaucoma. Table 2 displays that the value of adjusted $R$ square $=0.005$, indicating that the equation is predictive but weak because it is less than 1 .

Table 3 displays the outcomes of the ANOVA analysis as well as if there is a statistically significant difference between groups under consideration. Table 4 shows the findings of an investigation into the relationship between glaucoma and gender using the chi-squared test.

The significance value is $0.202(\mathrm{p}=0.202)$, which is more than 0.05 . As a result, it entails accepting the alternative hypothesis and rejecting the null hypothesis, which states that there is no relationship between gender and glaucoma. In addition, the value of the constant $\mathrm{A}=1.053$ and the value of the coefficient $\mathrm{B}=-0.027$ are taken from Table 4 . Therefore, the prediction equation in Eq. (1) is as follows:

$$
Y=1.053+(-0.027) X
$$

Furthermore, the correlation between age and glaucoma was examined using a simple linear regression test, which yielded a result of adjusted $\mathrm{R}$ square $=0.054$, indicating that the equation is predictive but weak because it is less than 1 . The findings are shown in Table 5.

Table 1. The distribution of ranges of all ages included in the study

\begin{tabular}{ccc}
\hline Age & Frequency & Percent \\
\hline Less than 11 years & 18 & 13.2 \\
11-20 years & 3 & 2.2 \\
21-30 years & 7 & 5.1 \\
31-40 years & 5 & 3.7 \\
41-50 years & 4 & 2.9 \\
51-60 years & 22 & 16.2 \\
61-70 years & 45 & 33.1 \\
71-80 years & 27 & 19.9 \\
81-90 years & 5 & 3.7 \\
Total & 136 & 100.0 \\
\hline
\end{tabular}

Table 2. Simple liner regression (a. Predicators: (constant), Gender)

\begin{tabular}{ccccc}
\hline & \multicolumn{3}{c}{ Model Summary } \\
\hline Model & $\mathrm{R}$ & $\mathrm{R}$ square & Adjusted R Square & Std. Error of the Estimate \\
1 & $0.110^{\mathrm{a}}$ & 0.012 & 0.0005 & \\
\hline
\end{tabular}

Table 3. ANOVA analysis for glaucoma and gender

\begin{tabular}{ccccccc}
\hline & Model & Sum of Square & df & Mean Square & F & Sig. \\
\hline \multirow{3}{*}{1} & Regression & 0.024 & 1 & 0.024 & 1.647 & $0.202^{\mathrm{b}}$ \\
& Residual & 1.947 & 134 & 0.15 & & \\
\cline { 2 - 6 } & Total & 1.971 & 135 & & & \\
\cline { 2 - 6 } & \multicolumn{7}{c}{ a: dependent variable (glaucoma) } \\
& b: Predicators, constant (Gender)
\end{tabular}

Table 4. Chi-squared test of glaucoma and gender

\begin{tabular}{ccccccc}
\hline \multirow{2}{*}{ Model } & \multicolumn{2}{c}{ Unstandardized Coefficients } & Mean Square & \multirow{2}{*}{ t } & \multirow{2}{*}{ Sig. } \\
\cline { 3 - 5 } & B & Std. Error & Beta & & \\
\hline \multirow{2}{*}{1} & Constant & 1.053 & 0.032 & & 33.0096 & 0.000 \\
& Gender & -0.027 & 0.021 & -0.110 & -1.283 & 0.202 \\
\hline
\end{tabular}

Table 5. Simple linear regression of age

\begin{tabular}{ccccc}
\hline Model & R & R Square & Adjusted R Square & Std. Error of the Estimate \\
\hline 1 & $0.247^{\mathrm{a}}$ & 0.061 & 0.054 & 0.11752 \\
\hline
\end{tabular}


Table 6. ANOVA analysis for glaucoma and age

\begin{tabular}{|c|c|c|c|c|c|c|}
\hline & Model & Sum of Square & df & Mean Square & $\mathbf{F}$ & Sig. \\
\hline \multirow{3}{*}{1} & Regression & 0.120 & 1 & 0.120 & 8.675 & $0.004^{\mathrm{b}}$ \\
\hline & Residual & 1.851 & 134 & 0.120 & & \\
\hline & Total & 1.971 & 135 & & & \\
\hline
\end{tabular}

Table 7. Chi-squared test of glaucoma and age

\begin{tabular}{cccccccc}
\hline \multirow{2}{*}{ Model } & \multicolumn{2}{c}{ Unstandardized Coefficients } & Standardized Coefficients & \multirow{2}{*}{ t } & \multirow{2}{*}{ Sig. } \\
\cline { 3 - 5 } & $\mathbf{B}$ & Std. Error & Beta & & \\
\hline \multirow{2}{*}{1} & Constant & 1.087 & 0.027 & & 40.960 & 0.000 \\
& Age & -0.012 & 0.004 & -0.247 & -2.945 & 0.004 \\
\hline
\end{tabular}

Table 6 displays the results of the ANOVA analysis as well as if there is a statistically significant difference between the groups under consideration. Table 7 shows the findings of an investigation into the relationship between glaucoma and gender using the chi-squared test.

The value of Sig is 0.004 , which is less than the value of 0.05. As a result, there is a link between age and glaucoma, and the null hypothesis should be rejected in favor of the alternative hypothesis. In addition, the value of the constant $A$ $=1.087$ and the value of the coefficient $\mathrm{B}=-0.012$ are taken from Table 7. As a result, Eq. (2) depicts the prediction equation:
Similarly, linear regression, ANOVA and chi-squared tests were performed, to judge the relationship between glaucoma and hypertension, Tables 8-10. The findings uncover that the value of adjusted $\mathrm{R}$ square $=0.043$ and, therefore, the equation is predictive and weak because it is less than 1. Besides, the value of Sig is 0.008 , which is a value of less than 0.05 . Therefore, the null hypothesis should be rejected and accept the alternative hypothesis, meaning that there is a relationship between hypertension and the glaucoma. Moving to Table 10, the value of the constant $\mathrm{A}=0.935$ and the value of the coefficient $B=0.065$. Therefore, the prediction Eq. (3) is as follows:

$$
Y=0.935+0.065 X
$$

Table 8. Simple linear regression of Hypertension

\begin{tabular}{ccccc}
\hline Model & R & R Square & Adjusted R Square & Std. Error of the Estimate \\
\hline 1 & $0.225^{\text {a }}$ & 0.051 & 0.043 & 0.11816 \\
\hline \multicolumn{5}{c}{ a: Predicators, constant (Hypertension) }
\end{tabular}

Table 9. ANOVA analysis for glaucoma and Hypertension (ANOVA ${ }^{\mathrm{a}}$ )

\begin{tabular}{ccccccc}
\hline & Model & Sum of Square & df & Mean Square & F & Sig. \\
\hline \multirow{3}{*}{1} & Regression & 0.100 & 1 & 0.100 & 7.135 & $0.008^{\mathrm{b}}$ \\
& Residual & 1.871 & 134 & 0.014 & & \\
& Total & 1.971 & 135 & & \\
\multicolumn{5}{c}{ a: dependent variable (glaucoma) } \\
b: Predicators, constant (Hypertension)
\end{tabular}

Table 10. Chi-squared test of glaucoma and hypertension

\begin{tabular}{|c|c|c|c|c|c|c|}
\hline & \multirow{2}{*}{ Model } & \multicolumn{2}{|c|}{ Unstandardized Coefficients } & \multirow{2}{*}{$\begin{array}{c}\text { Standardized Coefficients } \\
\text { Beta }\end{array}$} & \multirow{2}{*}{$\mathbf{t}$} & \multirow{2}{*}{ Sig. } \\
\hline & & B & Std. Error & & & \\
\hline \multirow{2}{*}{1} & Constant & 0.935 & 0.031 & & 29.848 & 0.000 \\
\hline & Age & 0.065 & 0.024 & 0.225 & 2.671 & 0.008 \\
\hline
\end{tabular}

Table 11. Simple linear regression of diabetes

\begin{tabular}{ccccc}
\hline Model & R & R Square & Adjusted R Square & Std. Error of the Estimate \\
\hline 1 & $0.095^{\mathrm{a}}$ & 0.009 & 0.002 & 0.12072 \\
\hline
\end{tabular}

Table 12. ANOVA analysis for glaucoma and diabetes

\begin{tabular}{ccccccc}
\hline & Model & Sum of Square & df & Mean Square & F & Sig. \\
\hline \multirow{4}{*}{1} & Regression & 0.018 & 1 & 0.018 & 1.211 & $0.273^{\mathrm{b}}$ \\
& Residual & 1.953 & 134 & 0.015 & & \\
& Total & 1.971 & 135 & & \\
\multicolumn{5}{c}{ a: dependent variable (glaucoma) } \\
b: Predicators, constant (Diabetes)
\end{tabular}


Table 13. Chi-squared test of glaucoma and diabetes

\begin{tabular}{|c|c|c|c|c|c|c|}
\hline \multirow{2}{*}{\multicolumn{2}{|c|}{ Model }} & \multicolumn{2}{|c|}{ Unstandardized Coefficients } & \multirow{2}{*}{$\frac{\text { Standardized Coefficients }}{\text { Beta }}$} & \multirow[b]{2}{*}{$\mathbf{t}$} & \multirow{2}{*}{ Sig. } \\
\hline & & B & Std. Error & & & \\
\hline \multirow{2}{*}{1} & Constant & 0.976 & 0.036 & & 29.932 & 0.000 \\
\hline & Diabetes & 0.024 & 0.021 & 0.095 & 1.100 & 0.273 \\
\hline
\end{tabular}

Table 14. Simple linear regression relationship between hypertension and healing degree

\begin{tabular}{ccccc}
\hline Model & R & R Square & Adjusted R Square & Std. Error of the Estimate \\
\hline 1 & $0.181^{\mathrm{a}}$ & 0.033 & 0.026 & 0.47347 \\
\hline \multicolumn{5}{c}{ a: Predicators, constant (Hypertension) }
\end{tabular}

Table 15. ANOVA analysis for hypertension and healing degree (ANOVA ${ }^{a}$ )

\begin{tabular}{ccccccc}
\hline & Model & Sum of Square & df & Mean Square & F & Sig. \\
\hline \multirow{4}{*}{1} & Regression & 1.020 & 1 & 1.020 & 4.551 & $0.035^{\mathrm{b}}$ \\
& Residual & 30.039 & 134 & 0.224 & & \\
\hline \multicolumn{5}{c}{ Total } & 31.059 & 135 \\
\multicolumn{5}{c}{ a: dependent variable (healing degree) } \\
b: Predicators, constant (Hypertension)
\end{tabular}

Table 16. Chi-squared test of hypertension and healing degree

\begin{tabular}{ccccccc}
\hline \multirow{2}{*}{ Model } & \multicolumn{2}{c}{ Unstandardized Coefficients } & Standardized Coefficients & \multirow{2}{*}{ t } & \multirow{2}{*}{ Sig. } \\
\cline { 3 - 5 } & B & Std. Error & Beta & 11.097 & 0.000 \\
\multirow{2}{*}{1} & Constant & 1.394 & 0.126 & & \\
& Diabetes & 0.206 & 0.097 & 0.181 & 2.133 & 0.035 \\
\hline \multicolumn{7}{c}{ a: dependent variable (healing degree) }
\end{tabular}

Table 17. Simple liner regression relationship between diabetes and healing degree

\begin{tabular}{ccccc}
\hline Model & R & R Square & Adjusted R Square & Std. Error of the Estimate \\
\hline 1 & $0.286^{\mathrm{a}}$ & 0.082 & 0.075 & 0.46132 \\
\hline
\end{tabular}

Table 18. ANOVA analysis for diabetes and healing degree (ANOVA $\left.{ }^{a}\right)$

\begin{tabular}{ccccccc}
\hline & Model & Sum of Square & df & Mean Square & F & Sig. \\
\hline \multirow{2}{*}{1} & Regression & 2.541 & 1 & 2.541 & 11.941 & $0.001^{\text {b }}$ \\
& Residual & 28.518 & 134 & 0.213 & & \\
& Total & 31.059 & 135 & & \\
\multicolumn{5}{c}{ a: dependent variable (healing degree) } \\
b: Predicators, constant (Diabetes)
\end{tabular}

Table 19. Chi-squared test of diabetes and healing degree

\begin{tabular}{ccccccc}
\hline \multirow{2}{*}{ Model } & \multicolumn{2}{c}{ Unstandardized Coefficients } & Standardized Coefficients & \multirow{2}{*}{ t } & \multirow{2}{*}{ Sig. } \\
\cline { 3 - 5 } & B & Std. Error & Beta & 8.576 & 0.000 \\
\multirow{2}{*}{1} & Constant & 1.188 & 0.139 & & 3.456 & 0.001 \\
\hline & Diabetes & 0.282 & 0.082 & 0.286 & 3 &
\end{tabular}

In a similar manner, linear regression, ANOVA and chisquared tests were performed, to judge the relationship between glaucoma and diabetes in Tables 11-13. The findings show that the value of adjusted $\mathrm{R}$ square $=0.002$ and therefore the equation is predictive and weak because it is less than 1 . Also, the value of $\mathrm{Sig}=0.273$, which is a value higher than 0.05 . Therefore, the alternative hypothesis will be rejected and accepted the null hypothesis, meaning that there is no relationship between diabetes and the glaucoma. The value of the constant $\mathrm{A}$ in Table 13 is 0.976 , and the value of the coefficient B is 0.024 . Therefore, the prediction equation is as follows in the Eq. (4):

$$
Y=0.976+0.024 X
$$

The relationship between hypertension and healing degree was tested using linear regression, ANOVA and chi-squared tests and the results are shown in Tables 14-16. According to the results, the value of adjusted $\mathrm{R}$ square $=0.026$ and, therefore, the equation is predictive and weak because it is less than 1. Besides, the findings also show that the value of Sig is 0.035 , which is a value of less than 0.05 . Therefore, the null hypothesis should be rejected and accepted as the alternative hypothesis, meaning that there is a relationship between hypertension and healing. Moving to the last Table, the outcomes uncover that the value of the constant $\mathrm{A}=1.394$ and the value of the coefficient $B=0.206$. Therefore, the prediction equation is as follows in Eq. (5):

$$
Y=1.394+0.206 X
$$

Similarly, the relationship between diabetes and healing degrees was tested using linear regression, ANOVA and chisquared tests and the results are shown in Tables 17-19. The 
value of adjusted $\mathrm{R}$ square $=0.075$. Accordingly, the equation is predictive and weak because it is less than 1 . Also, the value of Sig $=0.001$, which is a value of less than 0.05 . Therefore, the null hypothesis should be rejected and accepted as the alternative hypothesis, meaning that there is a relationship between diabetes and healing degree. From Table 19, the value of the constant $\mathrm{A}=1.188$ and the value of the coefficient $\mathrm{B}=$ 0.282 . Therefore, the prediction equation is as follows in Eq. (6):

$$
Y=1.188+0.282 X
$$

In terms of geographical location, we find that the highest percentage of casualties is in Baghdad. This is due to the greater population weight as the capital. The rest of the central provinces are similar in terms of infection ratio, except for Diyala and Karbala (5.882), also because of population density.

However, the further south we go, the higher the ratio of infections, with Maysan ranking second in injuries (13.97), Dhi Qar third (12.5), Basra fourth (10.29), and so on.

This is due to the fact that most of the professions in these provinces are characterized by hard physical effort, such as farming and raising animals and poultry, where physical and psychological stress factors are high.

As for the climatic factor, it was excluded after it was found that the temperatures and the rate of rainfall are very close. Table 20 shows the distribution of patients by geographical location of the country.

Table 20. Distribution of patients by geographical location of the country included in the study

\begin{tabular}{cccc}
\hline Provinces Location & Provinces & No. Patients & Percent \\
\hline & Baghdad & 33 & 24.264 \\
& Diyala & 8 & 5.882 \\
& Anbar & 4 & 2.941 \\
Central Provinces & Babyion & 5 & 3.676 \\
& Karbala & 8 & 5.882 \\
& Wasit & 3 & 2.205 \\
& Basra & 14 & 10.294 \\
& Qadisiyah & 7 & 5.147 \\
Southern Provinces & Najaf & 12 & 8.823 \\
& Maysan & 19 & 13.97 \\
& Dhi Qar & 17 & 12.5 \\
& Muthanna & 6 & 4.411 \\
& & 136 & 100.0 \\
\hline
\end{tabular}

\section{DISCUSSION}

Using a cohort cross-sectional observational approach, this study was conducted on the Iraqi population to evaluate the most common risk factors. Gender differences in glaucoma type preferences were discovered to be consistent with prior research that indicated no obvious gender preference for open angle glaucoma (POAG) [20]. Furthermore, the findings indicate that women are at a higher risk of angle closure glaucoma $[21,22]$.

Chi-squared analysis revealed that there is a relationship between age and the glaucoma, the older the subject, the more susceptible he/she to accrue glaucoma, which is in accordance with the reported cases $[17,18]$.

Hypertension is a key risk factor for a variety of diseases; roughly 1.13 billion adults, or around 22\% of the world's population, have hypertension [23]. Similar to previous studies $[24,25]$, the current investigation discovered a link between hypertension and glaucoma. Furthermore, the current investigation found a link between hypertension and healing degree [24]. Diabetes Mellitus (DM) prevalence in 2017 reached 425 million worldwide (9.0\% among adults) [26]. Zhou et al. [27] conducted a meta-analysis of case-control and reported that individuals with DM have an increased risk of developing POAG. In the current study, no such relationship was found, probably due to the sample size of the current study (only 136). Nevertheless, data from the current study uncovered that there is a relationship between diabetes and healing degree [28].

\section{CONCLUSION}

Incident cases were drawn from glaucoma patients' crosssectional data to explore gender disparities, age structure, and glaucoma risk factors. The current study finds there is a link between gender and glaucoma. It was also found that the geographical location is important in terms of increasing the number of injuries, as there was no effect or link between diabetes and glaucoma. On the other hand, current findings did not find a significantly greater incidence rate for females compared to males, nor did they find a link between diabetes and glaucoma. In addition, the current study uncovered that the incidence and prevalence of glaucoma increases with age and hypertension. As a result, the present findings may aid in the development of intervention strategies that will raise patient and physician awareness and, as a result, minimize the occurrence of glaucoma in the future.

\section{ACKNOWLEDGMENT}

We are grateful to Eye clinic at Ibn Al-Haitham Hospital in Bagdad, Iraq for providing the data.

\section{REFERENCES}

[1] Thulasiraj, R.D., Nirmalan, P.K., Ramakrishnan, R., et al. (2003). Blindness and vision impairment in a rural south Indian population: The Aravind comprehensive eye survey. Ophthalmology, 110(8): 1491-1498. https://doi.org/10.1016/S0161-6420(03)00565-7

[2] Kapetanakis, V.V., Chan, M.P., Foster, P.J., Cook, D.G., Owen, C.G., Rudnicka, A.R. (2016). Global variations and time trends in the prevalence of primary open angle glaucoma (POAG): A systematic review and metaanalysis. British Journal of Ophthalmology, 100(1): 8693. https://doi.org/10.1136/bjophthalmol-2015-307223

[3] Chen, S.Y., Yieh, F.S., Liao, W. L., Li, T.C., Hsieh, C.L. (2020). Effect of acupuncture on intraocular pressure in glaucoma patients: A single-blinded, randomized, controlled trial. Evidence-Based Complementary and Alternative $\quad$ Medicine, 2020: 7208081. https://doi.org/10.1155/2020/7208081

[4] Wostyn, P., De Groot, V., Van Dam, D., Audenaert, K., Killer, H.E., De Deyn, P.P. (2017). The glymphatic hypothesis of glaucoma: A unifying concept incorporating vascular, biomechanical, and biochemical aspects of the disease. BioMed Research International, 2017: 5123148. https://doi.org/10.1155/2017/5123148

[5] Landi, L., Casciaro, F., Telani, S., Traverso, C.E., Harris, A., Verticchio Vercellin, A.C., Saint, L., Iester, M. (2019). Evaluation of cerebrospinal fluid pressure by a formula and its role in the pathogenesis of Glaucoma. Journal of 
Ophthalmology,

2019:

1840481.

https://doi.org/10.1155/2019/1840481

[6] Eid, T.M., el-Hawary, I., El-Menawy, W. (2009). Prevalence of glaucoma types and legal blindness from glaucoma in the western region of Saudi Arabia: A hospital-based study. International Ophthalmology, 29(6): 477-483. https://doi.org/10.1007/s10792-008-9269-4

[7] Hashemi, H., Mohammadi, M., Zandvakil, N., Khabazkhoob, M., Emamian, M.H., Shariati, M., Fotouhi, A. (2019). Prevalence and risk factors of glaucoma in an adult population from Shahroud, Iran. Journal of Current Ophthalmology, $31(4)$ : $366-372$. https://doi.org/10.1016/j.joco.2018.05.003

[8] Lim, Z.W., Chee, M.L., Thakur, S., Fang, X., Da Soh, Z., Majithia, S., Teo, Z.L., Sabanayagam, C., Wong, T.Y., Cheng, C.Y., Tham, Y.C. (2021). Albuminuria and primary open-angle glaucoma: The Singapore Chinese Eye Study (SCES). British Journal of Ophthalmology, 105(5): 669-673. http://dx.doi.org/10.1136/bjophthalmol-2020-315920

[9] Rahman, M.M., Rahman, N., Foster, P.J., Haque, Z., Zaman, A.U., Dineen, B., Johnson, G.J. (2004). The prevalence of glaucoma in Bangladesh: A population based survey in Dhaka division. British Journal of Ophthalmology, 88(12):

1493-1497.

http://dx.doi.org/10.1136/bjo.2004.043612

[10] Khanna, R.C., Murthy, G. V., Giridhar, P., Marmamula, S., Pant, H.B., Shantha, G.P.S., Chakrabarti, S., Gilbert, C.E., Rao, G.N. (2018). Glaucoma-associated long-term mortality in a rural cohort from India: the Andhra Pradesh Eye Disease Study. British Journal of Ophthalmology, 102(11): $1477-1482$ http://dx.doi.org/10.1136/bjophthalmol-2017-311654

[11] Zhong, H., Li, J., Li, C., Wei, T., Cha, X., Cai, N., Luo, T., Yu, M., Yuan, Y. (2012). The prevalence of glaucoma in adult rural Chinese populations of the Bai nationality in Dali: The Yunnan minority eye study. Investigative Ophthalmology \& Visual Science, 53(6): 3221-3225. https://doi.org/10.1167/iovs.11-9306

[12] Weinreb, R.N., Leung, C.K., Crowston, J.G., Medeiros, F.A., Friedman, D.S., Wiggs, J.L., Martin, K.R. (2016). Primary open-angle glaucoma. Nature Reviews Disease Primers, 2(1):

16067. https://doi.org/10.1038/nrdp.2016.67

[13] Sun, X., Dai, Y., Chen, Y., Yu, D.Y., Cringle, S.J., Chen, J., Kong, X., Wang, X., Jiang, C. (2017). Primary angle closure glaucoma: what we know and what we don't know. Progress in Retinal and Eye Research, 57: 26-45. https://doi.org/10.1016/j.preteyeres.2016.12.003

[14] Souzeau, E., Glading, J., Keane, M., Ridge, B., Zhou, T., Burdon, K.P., Craig, J.E. (2014). Predictive genetic testing experience for myocilin primary open-angle glaucoma using the Australian and New Zealand registry of advanced Glaucoma. Genetics in Medicine, 16(7): 558-563. https://doi.org/10.1038/gim.2013.196

[15] Kuang, T.M., Zhang, C., Zangwill, L.M., Weinreb, R.N., Medeiros, F.A. (2015). Estimating lead time gained by optical coherence tomography in detecting glaucoma before development of visual field defects. Ophthalmology, $\quad$ 122(10): 2002-2009 https://doi.org/10.1016/j.ophtha.2015.06.015

[16] Pakravan, M., Yazdani, S., Javadi, M.A., et al. (2013). A population-based survey of the prevalence and types of glaucoma in central Iran: The Yazd eye study. Ophthalmology, 120(10): 1977-1984. https://doi.org/10.1016/j.ophtha.2013.02.029

[17] Haddad, M.F., Bakkar, M.M., Abdo, N. (2017). Public awareness of common eye diseases in Jordan. BMC Ophthalmology, 17(1): 177. https://doi.org/10.1186/s12886-017-0575-3

[18] Samy El Gendy, N.M., Abdel-Kader, A.A. (2018). Erratum to "prevalence of selected eye diseases using data harvested from ophthalmic checkup examination of a cohort of two thousand middle eastern and North African subjects". Journal of Ophthalmology, 2018: 8049475. https://doi.org/10.1155/2018/8049475

[19] Alkhalaileh, F., Hamdan, M., AlRyalat, S.A. (2018). Central corneal thickness in a Jordanian population and its association with different types of Glaucoma: Crosssectional study. BMC Ophthalmology, 18(1): 279. https://doi.org/10.1186/s12886-018-0944-6

[20] Vajaranant, T.S., Nayak, S., Wilensky, J.T., Joslin, C.E. (2010). Gender and glaucoma: What we know and what we need to know. Current Opinion in Ophthalmology, 21(2):

91-99. https://dx.doi.org/10.1097\%2FICU.0b013e3283360b7e

[21] Khachatryan, N., Pistilli, M., Maguire, M.G., et al. (2019) Primary Open-Angle African American Glaucoma Genetics (POAAGG) Study: Gender and risk of POAG in African Americans. PloS One, 14(8): e0218804. https://doi.org/10.1371/journal.pone.0218804

[22] Tehrani, S. (2015). Gender difference in the pathophysiology and treatment of glaucoma. Current Eye Research, $40(2)$ : 191-200. https://doi.org/10.3109/02713683.2014.968935

[23] Messerli, F.H., Williams, B., Ritz, E. (2007). Essential hypertension. The Lancet, 370(9587): 591-603. https://doi.org/10.1016/S0140-6736(07)61299-9

[24] Chung, H.J., Hwang, H.B., Lee, N.Y. (2015). The association between primary open-angle glaucoma and blood pressure: two aspects of hypertension and hypotension. BioMed Research International, 2015: 827516. https://doi.org/10.1155/2015/827516

[25] Leske, M.C., Wu, S.Y., Hennis, A., Honkanen, R., Nemesure, B., BESs Study Group. (2008). Risk factors for incident open-angle glaucoma: The Barbados eye studies. Ophthalmology, 115(1): 85-93. https://doi.org/10.1016/j.ophtha.2007.03.017

[26] Teo, Z.L., Tham, Y.C., Yu, M.C.Y., et al. (2021). Global prevalence of diabetic retinopathy and projection of burden through 2045: Systematic review and metaanalysis. Ophthalmology, 128(11): 1580-1591. https://doi.org/10.1016/j.ophtha.2021.04.027

[27] Zhou, M., Wang, W., Huang, W., Zhang, X. (2014). Diabetes mellitus as a risk factor for open-angle glaucoma: A systematic review and meta-analysis. PloS One, 9(8): e102972. https://doi.org/10.1371/journal.pone.0102972

[28] Costa, L., Cunha, J.P., Amado, D., Pinto, L.A., Ferreira, J. (2015). Diabetes mellitus as a risk factor in glaucoma's physiopathology and surgical survival time: A literature review. Journal of Current Glaucoma Practice, 9(3): 8185. https://dx.doi.org/10.5005\%2Fjp-journals-100081190 